\title{
Corrosion Resistance of Nickel-Based Alloy to Gaseous Hydrogen Iodide Decomposition Environment in Thermochemical Water-Splitting Iodine-Sulfur Process
}

\author{
Yu Kamiji, Kaoru Onuki, and Shinji Kubo
}

\begin{abstract}
Japan Atomic Energy Agency (JAEA) has been conducting research and development on the iodine-sulfur (IS) thermochemical water-splitting process for hydrogen production as one of the heat applications of High Temperature Gas-Cooled Reactor. The iodine-sulfur (IS) process is one of the most promising thermochemical process because of its potential for large-scale, economical and $\mathrm{CO}_{2}$ free hydrogen production. The IS process consists three chemical reactions: Bunsen reaction, sulfuric acid (H2SO4) decomposition reaction and hydrogen iodide (HI) decomposition reaction. In each reaction, high corrosion resistance is required of the construction materials since highly corrosive chemicals such as $\mathrm{HI}$, iodine and $\mathrm{H}_{2} \mathrm{SO}_{4}$ are used as working fluids in the various phases over a wide temperature range.

HI may be decomposed in gas phase using solid catalysts at temperatures around $500^{\circ} \mathrm{C}$. We fabricated a $\mathrm{HI}$ decomposer and examined corrosion of test specimens made of Nickelbased alloy (Hastelloy C-276) set in the actual HI decomposition environment, using pure $\mathrm{HI}$ as the feed gas. The experiments were carried out at $500^{\circ} \mathrm{C}$ and atmospheric pressure for $100 \mathrm{~h}$ in total. Corrosion rates were evaluated from the weight change of each specimen after exposure. Test specimens set in the catalyst layer suffered relatively severe corrosion $(<0.75 \mathrm{~mm} / \mathrm{y})$ in comparison with those set before the catalyst layer $(<0.52 \mathrm{~mm} / \mathrm{y})$. It is noted that the observed corrosion rates were larger than those of previous studies performed in the co-existence of steam.
\end{abstract}

Index Terms-Hydrogen production, thermochemical process, water splitting, iodine-sulfur process, hydrogen iodide, iodine, corrosion, nickel-based alloy.

\section{INTRODUCTION}

Japan Atomic Energy Agency (JAEA) has been conducting research and development on the iodine-sulfur (IS) thermochemical process for water-splitting hydrogen production, which is for one of the heat applications using high temperature gas-cooled reactors [1]. Fig. 1 shows schematics of the IS process. This process is one of promising thermochemical hydrogen production process because of its potential for large-scale, economical, and $\mathrm{CO}_{2}$ free hydrogen production. The IS process consists of three chemical reactions as follows:

$$
\mathrm{I}_{2}+\mathrm{SO}_{2}+2 \mathrm{H}_{2} \mathrm{O} \rightarrow \mathrm{H}_{2} \mathrm{SO}_{4}+2 \mathrm{HI}, 100^{\circ} \mathrm{C}
$$

Manuscript received July 25, 2018; revised October 16, 2018.

The authors are with the Japan Atomic Energy Agency/HTGR Hydrogen and Heat Application Research Center, Oarai, Japan (e-mail: kamiji.yu@jaea.go.jp, onukikaoru@jaea.go.jpp, shinjikubo@jaea.gp.jp).

$$
\begin{gathered}
\mathrm{H}_{2} \mathrm{SO}_{4} \rightarrow \mathrm{SO}_{2}+\mathrm{H}_{2} \mathrm{O}+1 / 2 \mathrm{O}_{2}, 900^{\circ} \mathrm{C} \\
2 \mathrm{HI} \rightarrow \mathrm{I}_{2}+\mathrm{H}_{2} 500^{\circ} \mathrm{C}
\end{gathered}
$$

Bunsen reaction (1) produces sulfuric acid $\left(\mathrm{H}_{2} \mathrm{SO}_{4}\right)$ and hydrogen iodide $(\mathrm{HI})$ from iodine $\left(\mathrm{I}_{2}\right)$, sulfur dioxide gas $\left(\mathrm{SO}_{2}\right)$ and raw material of water $\left(\mathrm{H}_{2} \mathrm{O}\right) . \mathrm{H}_{2} \mathrm{SO}_{4}$ is decomposed into $\mathrm{SO}_{2}, \mathrm{H}_{2} \mathrm{O}$, and product oxygen $\left(\mathrm{O}_{2}\right)$ by the reaction (2). Also, $\mathrm{HI}$ is decomposed into $\mathrm{I}_{2}$ and product hydrogen $\left(\mathrm{H}_{2}\right)$ by the reaction (3). As mentioned above, the IS process has highly corrosive environments of liquid or gas phase in wide temperature range. To realize industrial hydrogen production by the IS process, high corrosionresistant structural materials are required to construct largescale chemical reactors.

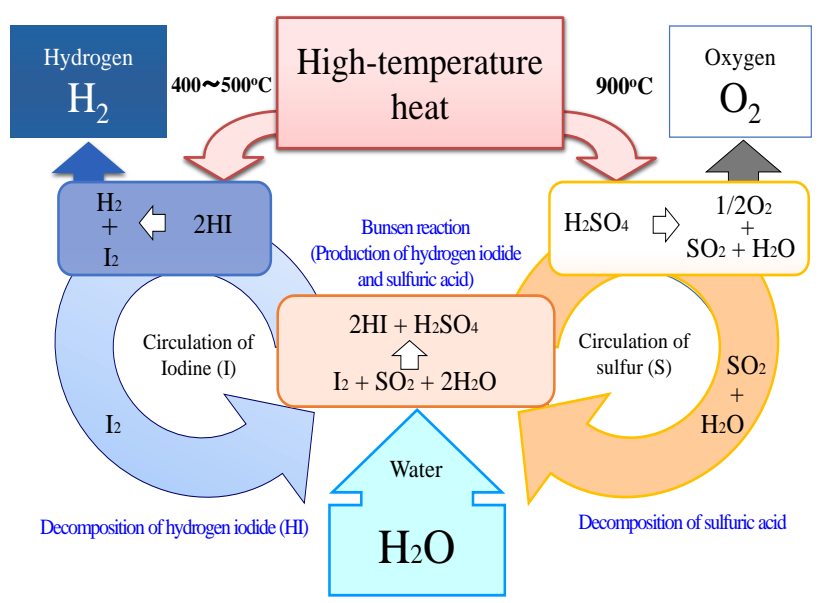

Fig. 1. Schematic diagram of the IS process.

In the HI decomposition reaction (3) environment, structural materials are attacked by gaseous halogen compounds such as $\mathrm{HI}$ and $\mathrm{I}_{2}$ around $500^{\circ} \mathrm{C}$. Candidate structural materials were e screened by corrosion resistant tests [2]-[6] in the HI decomposition reaction (3) environment. The studies found that ceramic materials such as alumina, mullite, $\mathrm{SiC}$ etc. have high corrosion resistance for HI decomposition environment. For metallic materials, the studies report that nickel-based alloy such as Hastelloy C-276, MAT21, Haynes214 and pure metals of Molybdenum (Mo) and Titanium (Ti) showed acceptable corrosion resistance. Considering commercial large-scale $\mathrm{H}_{2}$ production, ceramic materials have difficulty to fabricate large-scale reactors, so that metallic materials are preferable.

Protective oxide layers are important in corrosion mechanism for the metallic materials. The corrosion test environments in studies mentioned above contain water 
vapor which has ability to form the protective oxide layer on surface of structural materials. Looking at practical HI decompose reactor, dry HI (without water vapor) will be fed to the HI decomposer, because of improved process using an electro-electrodialysis (EED) to reduce water vapor for process efficiency improvement [7].

In this study, corrosion resistance of a metal candidate material of Hastelloy C-276 was evaluated to clarify corrosion resistance in practical HI decomposition environment where the dry $\mathrm{HI}$ gas reaction may be carried out using catalyst at ca. $500^{\circ} \mathrm{C}$ with decomposition ratio of around $20 \%$ [8].

\section{EXPERIMENTAL}

A schematic of corrosion test apparatus is shown in Fig. 2. This test apparatus consisted of a HI decomposer equipped with a mantle heater, a reactant $\mathrm{HI}$ gas cylinder, a diluent $\mathrm{N}_{2}$ gas cylinder, an air-cooled $\mathrm{I}_{2}$ trap vessel, an undecomposed HI gas scrubber filled with water, a residual gas scrubber packed with silica gel, and an active carbon bed. The reactant HI gas (>99.999\%, Godo Shigen Co.,Ltd.) was fed through mass flow controller (MFC) (Type T1000M, Fujikin). Diluent $\mathrm{N}_{2}$ gas was fed through MFC (Type SEC400, Horiba Ltd.) to downstream of the HI decomposer. Effluent gas flowrate was measured by a volumetric positive displacement type flowmeter (Type W-NK, Shinagawa Corp.). $\mathrm{H}_{2}$ concentration in effluent gas was analyze by a gas chromatograph (MS-5A column, Type GC-8A, Shimadzu Corp.).

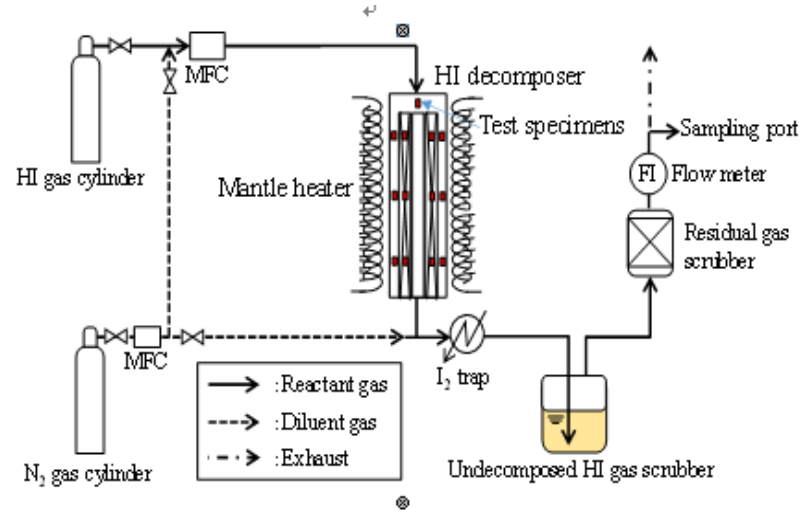

Fig. 2. Schematic of corrosion test apparatus.

Fig. 3 shows a schematic of the HI decomposer and location of the test specimens. The HI decomposer was a radial-flow type fixed-bed reactor [9]. This reactor consisted of coaxial tubes made of Hastelloy C-276. Active carbon catalysts $(350 \mathrm{~g})$ were filled in between the middle tube and the innermost tube. The test specimens were placed before the catalyst layer and also inside the catalyst layer to investigate influence of coexistence of decomposed products of $\mathrm{I}_{2}$ and $\mathrm{H}_{2}$ gas in the $\mathrm{HI}$ gas on corrosion resistance.

Fig. 4 shows a picture of the test specimen; dimensions were $10 \mathrm{~mm} \times 20 \mathrm{~mm} \times 1 \mathrm{~mm}$ with a hole for hanging to place. In addition to the test specimens made of Hastelloy C-276, those of JIS-SUS316 were examined for comparison to the candidate material of the Hastelloy C-276. Surfaces of the specimens were polished with emery papers (\#1200).

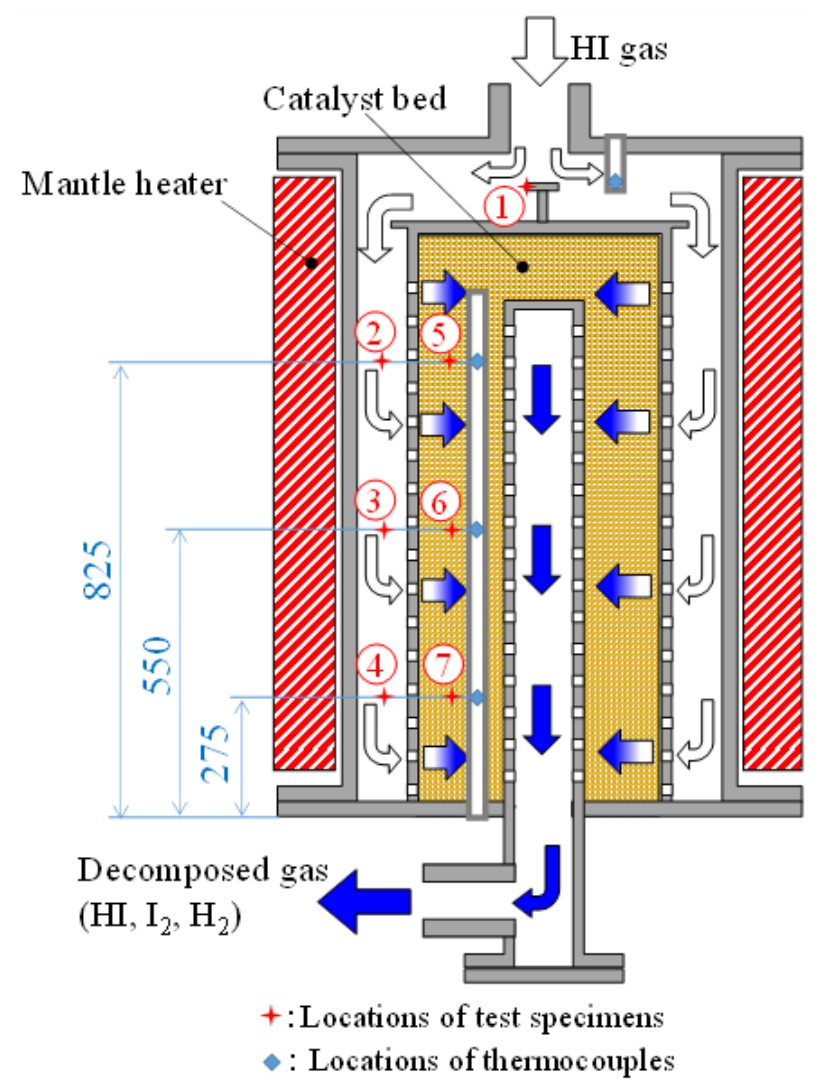

Fig. 3. Schematic of the HI decomposer and locations of test specimens.

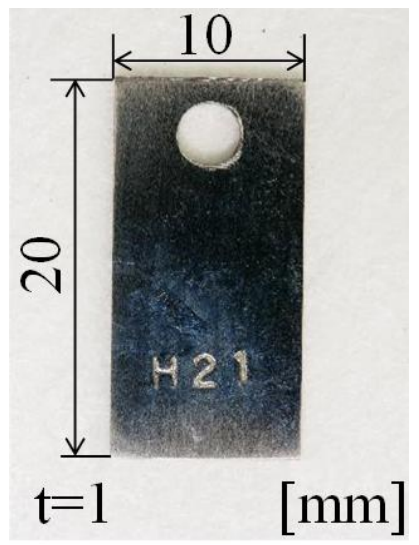

Fig. 4. Dimensions of test specimen.

In the corrosion test, HI gas of $167 \sim 227 \mathrm{~cm}^{3} / \mathrm{min}$ was supplied to the reactor of $500^{\circ} \mathrm{C}$ at atmospheric pressure for 10 hours. The flow rate of effluent gas was monitored continuously, while the $\mathrm{H}_{2}$ concentration was analyzed periodically. The test was repeated 10 times so as to attain the total exposure time of 100 hours. Corrosion rates were determined with weight change of the test specimens weighed before and after corrosion.

\section{RESULTS AND DisCUSSION}

Fig. 5 shows an evolution of $\mathrm{HI}$ conversion ratio during the 10th cycle of the corrosion test. The observed HI conversion ratio was close to the chemical equilibrium value, indicating that the $\mathrm{HI}$ decomposition reaction proceeded as planned. Higher conversion ratio than the equilibrium one was observed in the initial stage, which may be due to adsorption of product $I_{2}$ into the active carbon catalyst. 


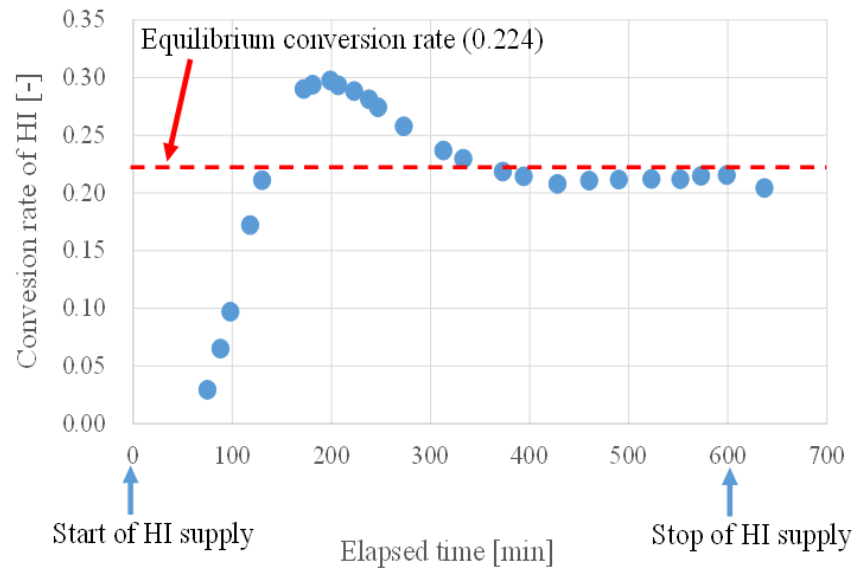

Fig. 5. An evolution of $\mathrm{HI}$ conversion ratio during the 10th cycle of the corrosion test.

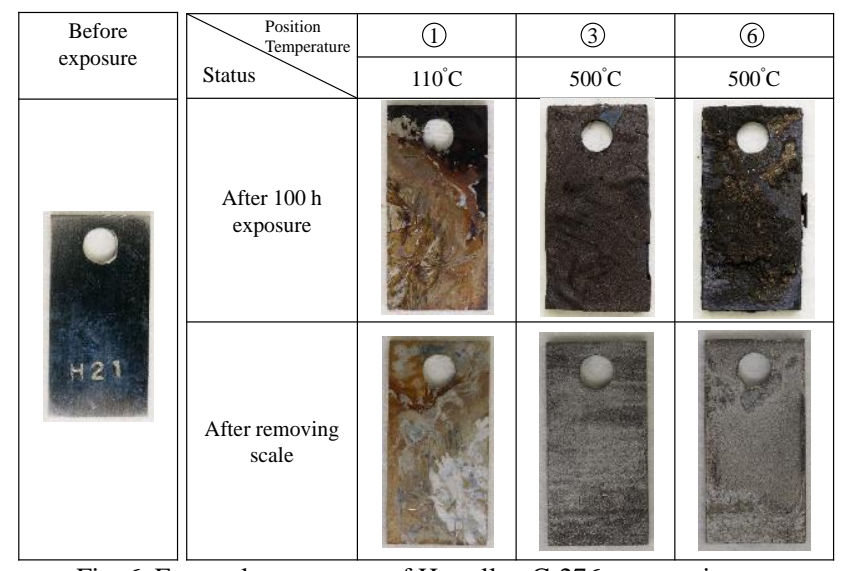

Fig. 6. External appearance of Hastelloy C-276 test specimens.

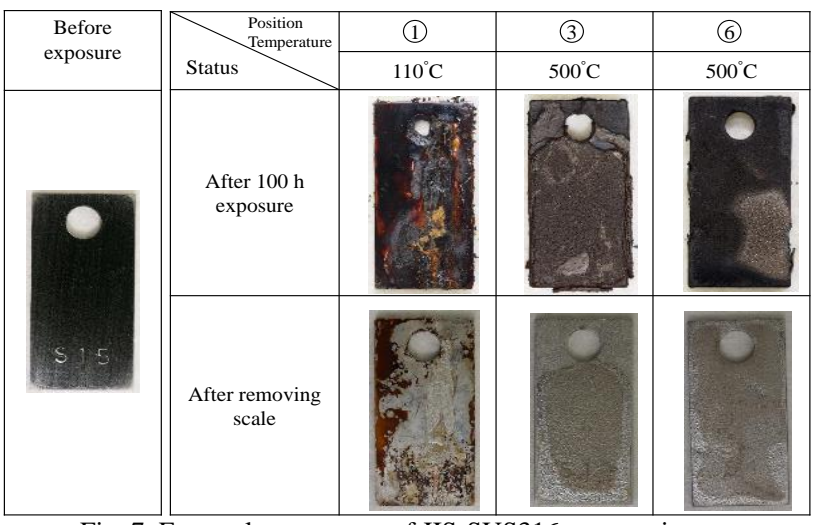

Fig. 7. External appearance of JIS-SUS316 test specimens.

The external appearances of the test specimens are shown in Fig. 6 (Hastelloy C-276) and Fig. 7 (JIS-SUS316). Here, the appearances of test specimens at position 1 (near gas inlet, $110^{\circ} \mathrm{C}$ ), position 3 (midpoint position of before catalyst layer, $500^{\circ} \mathrm{C}$ ) and position 6 (midpoint position of inside catalyst layer, $500^{\circ} \mathrm{C}$ ) are shown as typical examples; the upper half of figure is specimens after 100 hours exposure, and the lower half of figure shows specimens after removing scales from the surface of 100 hours exposure specimens. Surfaces of specimens were uniformly roughened in position 3 and 6 , in that the general corrosion occurred. The scales showed deliquescence. Thus, they did not include seemingly molybdenum iodide which was stable to moist air [10]. Also, They had low close adhesion and were easily removed by ultrasonic washing using pure water. The surface roughness of the specimens at position 1 was much milder than those in position 3 and 6 , which probably due to lower temperature of the environment.

TABLE I: SUMMARY OF CORROSION RATES OF THE TEST SPECIMENS

\begin{tabular}{|c|c|c|c|c|}
\hline \multirow{2}{*}{} & Position & \multirow{2}{*}{$\begin{array}{c}\text { Temperature } \\
{\left[{ }^{\circ} \mathrm{C}\right]}\end{array}$} & \multicolumn{2}{|c|}{ Corrosion rate } \\
\cline { 4 - 6 } & & $\mathrm{g} / \mathrm{m}^{2} / \mathrm{h}$ & $\mathrm{mm} / \mathrm{y}$ \\
\hline \multirow{3}{*}{$\begin{array}{c}\text { Hastelloy } \\
\text { C-276 }\end{array}$} & 1 & 110 & 0.011 & 0.01 \\
\cline { 2 - 5 } & 3 & 500 & 0.523 & 0.52 \\
\cline { 2 - 5 } & 6 & 500 & 0.762 & 0.75 \\
\hline \multirow{3}{*}{$\begin{array}{c}\text { IS- } \\
\text { SUS316 }\end{array}$} & 1 & 110 & 0.339 & 0.37 \\
\cline { 2 - 5 } & 3 & 500 & 5.944 & 6.53 \\
\cline { 2 - 6 } & 6 & 500 & 5.249 & 5.76 \\
\hline
\end{tabular}

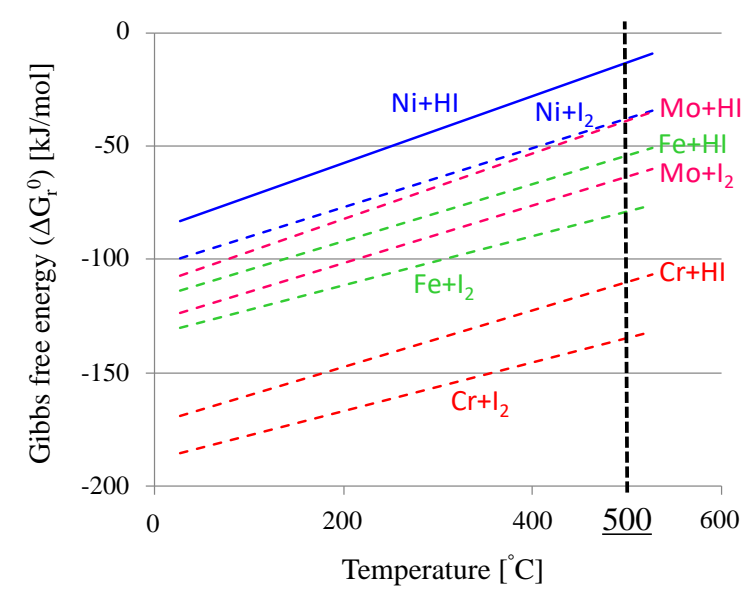

Fig. 8. the standard Gibbs free energy changes of metal iodide formation reactions.

Table I summarizes the average corrosion rates. The results indicate that the corrosion rates are low level of the specimens at position 1 . On the other hand, the corrosion rates of the specimens at positions 3 and 6 were rather high: $0.52 \sim 0.75 \mathrm{~mm} / \mathrm{y}$ for Hastelloy C-276 and $5.76 \sim 6.53$ $\mathrm{mm} / \mathrm{y}$ for JIS-SUS316. It should be noted that the observed corrosion rates, even that of Hastelloy C-276, are much higher than those observed in previous studies, which performed in gaseous $\mathrm{HI}$ environments in the presence of gaseous $\mathrm{H}_{2} \mathrm{O}$. Also, it is noted that the corrosion rate of the specimen made of Hastelloy C-276 placed inside catalyst layer, position 6 , is slightly higher than that placed outside catalyst layer, position 3 . Fig. 8 shows the standard Gibbs free energy changes of metal iodide formation reactions. From the view point of thermodynamics, the reactivity of I2 is higher than that of HI. The higher corrosive action of the catalyst layer may be partly explained by this reactivity to form the metal iodides.

\section{CONCLUSIONS}

To evaluate corrosion resistance of candidate structural materials in practical environment, Hastelloy C-276, for the gaseous hydrogen iodide decomposition environment in thermochemical hydrogen production IS process, corrosion rates were examined by a 100 hours exposure test using test specimens in a $\mathrm{HI}$ decomposer operated at $500^{\circ} \mathrm{C}$ under atmospheric pressure, using pure $\mathrm{HI}$ as the corrosive gas. The following conclusions were obtained.

1) Hastelloy C-276 suffered much severer corrosion in 
comparison with the previous corrosion tests carried out in gaseous HI environments in the presence of gaseous $\mathrm{H} 2 \mathrm{O}$.

2) The environment of products (gaseous HI, I2, and H2) in active carbon catalyst layer exhibited higher corrosiveness than the environment of reactant (gaseous HI) in previous catalytic layer.

\section{ACKNOWLEDGMENT}

The authors would like to thank H. Aita for technical assistance with the experiments.

\section{REFERENCES}

[1] S. Kubo, N. Tanaka, J. Iwatsuki, S. Kasahara, Y. Imai, H. Noguchi, and K. Onuki, "R\&D status on thermochemical is process for hydrogen production at JAEA," Energy Procedia, vol. 29, no. 308, 2012.

[2] Y. Imai, Y. Kanda, H. Sasaki, and H. Togano, "Corrosion resistance of metallic materials in high temperature gases composed of iodine, hydrogen iodide and water (environment of the 3rd and 4th stage reactions)," Boshoku Gijutsu, vol. 31, pp. 714-721, 1982.

[3] K. onuki, I. Ioka, M. Futakawa, H. Nakajima, S. Shimizu, and I. Tayama, "Screening tests on materials of construction for the thermochemical is process," Zairyo-to-Kankyo, vol. 46, pp. 113-117, 1997.

[4] S. Kubo, M. Futakawa, K. Onuki, and A. Yamaguchi, "Adaptability of metallic structural materials to gaseous hi decomposition environment in thermochemical water-splitting iodine-sulfur process," Corrosion Engineering, vol. 62, no. 3, pp. 104-111, 2013.

[5] J. Y. Choi, Y. S. Kim, I. Sah, H. C. No, and C. Jang, "Corrosion resistance of alloys in high temperature hydrogen iodine gas environment for sulfur-iodine thermochemical cycle," International Journal of Hydrogen Energy, vol. 39, pp. 14557-14564, 2014
[6] W. Kondo, M. Kaneko, Y. Takemori, H. Sasaki, and K. Fujii, "Corrosion resistance of ceramic materials in high temperature gases composed of iodine, hydrogen iodide and water (environment of the 3rd and 4th stage reactions)," Boshoku Gijutsu, vol. 31, pp. 722-727, 1982.

[7] M. Yoshida, N. Tanaka, H. Okuda, and K. Onuki, "Concentration of HIx solution by electro-electrodialysis using Nafion 117 for thermochemical water-splitting IS process," International Journal of Hydrogen Energy, vol. 33, pp. 6913-6920, 2008.

[8] Y. Shindo, N. Ito, K. Haraya, T. Hakuta, and H. Yoshitome, "Kinetics of the catalytic decomposition of hydrogen iodide in the thermochemical hydrogen production," International Journal of Hydrogen Energy, vol. 9, no. 8, pp. 695-700, 1984.

[9] S. Kasahara, N. Tanaka, H. Noguchi, J. Iwatsuki, H. Takegami, and S. Kubo, "JAEA's R\&D on the thermochemical hydrogen production is process," in Proc. 7th International Topical Meeting on High Temperature Reactor Technology (HTR2014), Weihai, China, October 27-31, 2014, HTR2014-21233, Institute of Nuclear and New Energy Technology (INET), Tsinghua University.

[10] Gmelin Handbook of Inorganic and Organometallic Chemistry, $8^{\text {th }}$ ed. Springer-Verlag, p. 260, 1990.

Yu Kamiji was born in Tochigi, Japan, on 25th Sep. in 1984. He graduated from Utsunomiya University in Tochigi, Japan and got master degree in mechanical engineering, his study fields are fluid dynamics and flow visualization.

He worked for research of hydrogen supply chain of the nuclear hydrogen for the first two years in JAEA. After the Great East Japan earthquake on 11st Mar. 2011, he joined research of hydrogen safety, especially to prevent hydrogen explosion in nuclear facilities using passive autocatalytic recombiner. Additionally, he started research of the IS process hydrogen production from 2015 .

Mr. Kamij has the membership of Atomic Energy Society of Japan, the Japan Society of Mechanical Engineers, and the Visualization Society of Japan. 